\title{
The Role of Mindfulness in Treating Addictive Disorders and Rehabilitation Kathirasan $\mathbf{K}^{\star}$ \\ Centre for Mindfulness, Midview City, 573969, Singapore
}

\begin{abstract}
Mindfulness was originally introduced as a participatory medicine and complementary therapy in hospital settings in the late 1970s. Since then, countless research experiments on mindfulness interventions have shown positive results in the areas of physical and cognitive challenges with a strong impact on the latter. The connection between rehabilitation in the areas of addiction and mindfulness has also become a popular discussion since the advent of Mindfulness-Based Cognitive Therapy (MBCT) and Mindfulness-Based Relapse Prevention (MBRP) which are variants of mindfulness practices. Research findings suggest positive effects on relapse prevention for addiction and other associated disorders. While the results from these research findings appear to suggest that mindfulness can be favourable to positive change, it is important to (1) understand the uniqueness of this alternative treatment and relief; and (2) review results from trials and other studies. A review and discussion of mindfulness-based interventions (MBIs) provided significant insights into the uniqueness of mindfulness interventions in helping people with addiction.
\end{abstract}

\author{
Publication History: \\ Received: July 12, 2018 \\ Accepted: November 19, 2018 \\ Published: November 21, 2018
}

\section{Keywords:}

Mindfulness, Meditation, Addiction, Relapse prevention, Rehabilitation

\section{Introduction}

Mindfulness is "paying attention in a particular way: on purpose, in the present moment, and non-judgmentally" [1, p.4]. It is also a state of "awareness that emerges through paying attention on purpose, in the present moment, and non judgmentally to the unfolding of experience moment by moment" [2, p.145]. Richmond, Zerbo and Levounis [3, p.3] stated that mindfulness is a "state of mind that appreciates the flow of consciousness in real time and with acceptance." According to Garland, Froeliger and Howard [4], mindfulness practices involved two primary components which were 'focused attention' and 'open monitoring'.

Focused attention is the wilful practice where attention is placed on an object as well as acknowledging mental distractions while being in the practice. In mindfulness practices, different parts of the self is utilised to pay attention, such as the breath, bodily sensations, and sensory perceptions amongst others [5]. One common feature amongst mindfulness practices is the reduced usage of external devices for paying attention.

Open monitoring is about noticing present-moment experience without any judgement [6]. This second aspect of mindfulness is related to the ability of acceptance while being in the practice. According to Houlihan and Brewer [7] mindfulness training has two distinct components: maintaining attention and maintaining an attitude of acceptance toward the experience gained while paying attention.

While awareness is a desired end state of mindfulness through the practice of attention and acceptance, it can also be a practice of metacognition [8]. The practice of metacognition is not a third component of mindfulness but an intrinsic component of focused attention and open monitoring.

Further elements of mindfulness have been suggested by various authors. Attention, intention and attitude have been suggested by Shapiro, Carlson, Astin and Freedman [9]. Insight, exposure, non-attachment, enhanced mind-body functioning and integrated functioning by Brown, Ryan and Creswell [10]. Baer [11] suggested the following elements: exposure, cognitive change, self-management, relaxation and acceptance. Observing, describing, acting with awareness, non-judging of inner experience, and non-reactivity to inner experience were proposed by Baer, Smith, Hopkins, Krietemeyer and Toney [12].

Mindfulness can be described as both state and dispositional mindfulness. Dispositional mindfulness is also called trait mindfulness $[13,14]$. Dispositional mindfulness is defined as the effortless tendency to exhibit the elements of mindfulness [12] and also occurring as an innate trait in the general population [15]. State mindfulness however is a momentary condition and can be enhanced by mindfulness practices taught in Mindfulness Based Stress Reduction (MBSR) and Mindfulness Based Cognitive Therapy (MBCT). There are studies that claim that increasing state mindfulness can lead to dispositional mindfulness. Kiken, Garland, Bluth, Palsson and Gaylord [16, p.1] found that "increasing state mindfulness over repeated meditation sessions may contribute to a more mindful and less distressed disposition."

\section{First generation of mindfulness based interventions}

Mindfulness-based interventions (MBIs) have been increasing over the years [17]. The two early generations of MBIs and the most extensively employed and evaluated are the MBSR and MBCT [18]. The first type of MBI was developed in the University of Massachusetts by Jon Kabat-Zinn during the 1970s [19]. It was called Mindfulnessbased Stress Reduction (MBSR) and was designed or the relief of pain, stress and the effects of chronic health problems [13]. MBSR was also found to have positive effects on pain, anxiety and stress in individuals with chronic disorders [20].

"Corresponding Author: Mr. Kathirasan K, Centre for Mindfulness, Midview City, 573969, Singapore; E-mail: kathir@centreformindfulness.sg

Citation: Kathirasan K (2018) The Role of Mindfulness in Treating Addictive Disorders and Rehabilitation. Int J Psychol Behav Anal 4: 155. doi: https://doi. org/10.15344/2455-3867/2018/155

Copyright: (c) 2018 Kathirasan. This is an open-access article distributed under the terms of the Creative Commons Attribution License, which permits unrestricted use, distribution, and reproduction in any medium, provided the original author and source are credited. 
Another MBI called the Mindfulness Based Cognitive Therapy (MBCT) was developed in 2002 that was targeted at depression and its relapse $[21,22]$. The MBCT was developed based on the premise of the MBSR and Cognitive Behavioural Therapy (CBT) [23]. MBCT was also found to have a positive effect on depression, anxiety and fatigue in coronary heart disease, diabetes, cancer, cardiovascular disorders and arthritis [24].

Both MBSR and MBCT employed mindfulness practices such as the sitting meditation, awareness of breath meditation, body scan, breathing space, walking meditation, raisin practice and inquiries $[13,25]$. They are both conducted for groups of individuals and have a weekly session of 2-3 hours over a period of 8 weeks with a trained teacher and included daily home practices [26]. "Taken together, based on the theoretical underpinnings of MBIs and models of how they work, possible mechanisms connecting MBSR and MBCT with their beneficial effects include improvements in a number of variables including mindfulness, repetitive negative thinking, AMS, reperceiving, reactivity, nonattachment, nonaversive, self-awareness, self-regulation, self-transcendence, psychological flexibility, clarification of inner values, exposure, attentional control and regulation, body awareness, mind-body and integrated functioning, emotion regulation, self-compassion, compassion, insight, acceptance, relaxation and ethical practices" $[18$, p.3].

It is worthy to note that MBCT and MBSR were designed to address "chronic physical problems, who were managing pain, low mood and health-related anxiety" [24, p.75]. MBIs were found to share core components and intention for mindfulness to occur [17] However, Chiesa and Malinowski [27, p.404] stated that "the currently applied mindfulness-based interventions show large differences in the way mindfulness is conceptualized and practiced." They further stated that there were differences in the theoretical background, the ways of practicing mindfulness, some MBIs excluded meditation training and their aims seem to differ too more because of individual perspectives rather than the approach of MBI [27]. It seems "clear that alternative interventions differ considerably from MBSR and MBCT and each other in the duration and frequency of mindfulness practice involved, and the inclusion of mindfulness psychoeducation and nonmindfulness therapeutic ingredients" [18, p.2].

\section{Results of mindfulness}

Research in mindfulness has shown many positive results. Shonin and Van Gordon [28] have recorded ten unique results of Mindfulness which were: structural brain changes, reduced autonomic arousal, perceptual shift, increase in spirituality, greater situational awareness, values clarification, increase in self-awareness, addiction substitution, urge surfing and letting go. Among the listed results, structural brain changes appear to be the most significant result which may directly or indirectly influence the rest of the results.

It was found that the grey matter density changed in the bilateral amygdala with stress reduction associated with mindfulness practices [29]. In a review on the brain changes in meditators, it was found that there were changes in cortical thickness, less decline in grey matter volume and increase in grey matter density [30]. Meditation was also found to increase grey matter concentration in the part of brain that involved in learning and memory processes, emotion regulation, self-referential processing, and perspective taking [30]. Grey matter density changes were was also found in the amygdala and hippocampus [31]. Different types of meditative traditions were also seen to have similar and different types of changes in the brain which were cortical thickness, grey matter volume, grey matter density, hippocampal volume and diffusivity [32]. Dispositional mindfulness has also been linked to decreased grey matter volume in the right amygdala and the left caudate [33].

Creswell [34] recorded mindfulness positively impacting physical health, mental health, cognitive, affective and interpersonal outcomes. It was also found that mindfulness had a significant impact on addiction and addictive disorders.

Mindfulness practices leading to non-dual states have also been speculated [35] but with suggestive evidence albeit limited [36,37]. Generally, the results for mindfulness are positive.

\section{Adverse effects of mindfulness}

Mindfulness does have its downsides. Adverse effects were found to be uncommon for mindfulness except for known adverse effects on psychosocial outcomes and spirituality. However, it is possible that the adverse effects go unreported [38].

There has been recorded adverse effects for other types of meditation such as transcendental meditation, qigong and nonspecific relaxation-based meditative approaches [38]. Adverse effects were not limited to panic attacks, antisocial behaviour, impaired reality testing, dissociation, musculoskeletal pain, uncomfortable kinesthetic sensations, suicidal feelings and exhaustion [38].

Research by Briñol, Gascó, Petty and Horcajo [39] found that some mindfulness treatments could have pitfalls, "at least for some people and for some situations, particularly those in which positive thoughts are present" (p.46). Addiction to meditation was also known to be an adverse effect impacting psychological distress and interpersonal conflict among others [38]. Wilson, Mickes, Stolarz-Fantino, Evrard and Fantino [40, p.1567] discovered in their research that "a potential unintended consequence of mindfulness meditation in which memories become less reliable" where false memories were formed as compared to the control group whom engaged in mind-wandering.

Brendel [41] stated that some people used the techniques of mindfulness to withdraw themselves from critical thinking tasks which require more rational thinking process. Lustyk, Chawla, Nolan and Marlatt [42] found that mindfulness could lead to feelings of anxiety, feelings of intense dysphoria, feelings of mania, insomnia, increase risk of seizures, depersonalisation, derealisation, psychosis, depression and religious delusions amongst others.

Lustyk et al. [42] further stated that individuals should be screened before exploring any mindfulness practices and teachers of mindfulness should be well trained before embarking on teaching others. Crane et al. [43] asserted that for teachers, the two elements of good practice were supervision and personal mindfulness practices.

\section{Addiction}

Addiction has been defined as a habitual behaviour with both positive and negative outcomes; disease; an outcome of an imbalanced central nervous system, and in the recent times as a neurobiological disease and genetic [44]. Dependency, loss of control and impaired control with adverse effects also defined addiction [45]. Social aspects, co-morbid disorders, personality, biochemistry, neurocircuitry and genetics were factors found influence to addictive disorders [45]. In the 
recent times, addiction is commonly viewed as a disorder. The DSM-5 categorised addiction as "Substance-Related and Addictive Disorders" and listed nine type of substance addictions: alcohol; caffeine; cannabis; hallucinogens; inhalants; opioids; sedatives, hypnotics, and anxiolytics; stimulants; and tobacco [46]. Subsequently, gambling addiction has also been added to the aforementioned category but sex addiction, compulsive buying, internet addiction, or kleptomania were not considered [46].

Addiction viewed as a brain disease has allowed preventive measures and treatments to be more effective. However, the field of connecting addictions to neurobiology and neurocircuitry is still evolving [47] Changes in brain biochemistry has also allowed for further mitigation and management of addictions [48]. The neuro-addiction is processed through motivated attention, automaticity, reward processing, emotion regulation, stress reactivity, and inhibitory control [4].

\section{Types of Mindfulness-Based Interventions for Addictive Disorders}

The use of mindfulness interventions for treating addictive disorders is a recent phenomenon [7]. Literature suggests that MBIs are effective for the treatment of substance use disorders and reduced the susceptibility to relapse [49]. It has been hypothesised that MBIs can be effective in a wide range of addictions $[4,50,51]$.

Several MBIs have been designed and used for addiction rehabilitation. The MBSR, MBCT, MORE, MABT, MBRP and Vipassana, among a few, were modified to meet this need [51]. The MBSR and MBCT, being the first generation of MBIs, have been used with people with addictive disorders with effectiveness. Apart from these, several other second generation MBIs have also seen relatively positive outcomes.

\section{Mindfulness oriented recovery enhancement (MORE)}

Mindfulness Oriented Recovery Enhancement (MORE) is an intervention that fuses mindfulness practices, third wave cognitivebehavioural therapy (CBT) and positive psychology [52]. It is a 10 session program similar to the first generation MBIs [53].

\section{Mindfulness based relapse prevention (MBRP)}

Mindfulness Based Relapse Prevention (MBRP) is a 8 session program developed as a fusion of traditional relapse prevention strategies with mindfulness training. It was designed as an aftercare program for substance use disorders [54]. MBRP uses a similar approach of MBSR and MBCT to learn mental coping skills to notice and tolerate discomfort.

\section{Mindful awareness in body-oriented therapy (MABT)}

Mindful Awareness in Body-oriented Therapy (MABT) is an intervention that develops awareness of bodily stimuli and its relation with emotions and its regulation [55]. It is delivered weekly as a 90 minute program over 8 weeks [56].

\section{Mindfulness based addictiontreatment (MBAT)}

Mindfulness Based Addiction Treatment (MBAT) is a modification of MBCT with a special focus on nicotine dependence instead of depression. The structure of the intervention is known to be similar to MBCT [57].

\section{Vipassana meditation}

Vipassana Meditation is perhaps the only intervention that has strong Buddhist leanings as it investigates into the world to see its impermanence [58]. It is seen to have its roots in the Thai and Burmese Theravada Buddhist tradition. Vipassana is usually taught as a residential 10 day course (sometimes shorter) with almost the whole period spent in silence.

\section{Method}

\section{Literature search}

A literature search was conducted in Google Scholar and other internet search engines. Initial searches were conducted in April 2018. The search strings used were 'mindfulness addiction' OR 'mindfulness intervention' OR 'mindfulness addictive disorders' OR 'mindfulness treatment' AND (substance OR alcohol OR smoking OR sex OR workaholism OR gambling). In addition, 42 articles were retrieved from the published review of Li et al. [51].

\section{Selection of Sources}

The search included mindfulness studies published in English for a 11 year period from 2006 to 2017 . The studies included were (1) recorded effects of a mindfulness treatment for addictions; OR (2) used quasi-experimental designs, or randomized controlled trial (RCT) designs; OR (3) targeted client populations with problems (alcohol, substance, smoking, sex, workaholism and gambling). The studies were excluded were (1) book reviews, books, book chapters, dissertations, (2) used interventions that did not teach formal mindfulness practices (e.g., Acceptance and Commitment Therapy, Dialectical Behaviour Therapy). Based on the above selection criteria, a total of 55 studies were included in this review and meta-analysis.

\section{Outcomes Variables}

The primary outcomes studied in this review and meta-analysis were reduction in the amount and frequency of substance use, reduced craving, decrease in relapse, reduced dependency, reduction in severity, reduced distress, and increase in abstinent rate. The secondary outcomes studied were psycho-social improvement and improved mental health.

\section{Results}

The therapeutic effect of mindfulness interventions have been widely acknowledged [28]. MBIs were found to teach individuals to notice bodily and mental states instead of reacting to them, thus leading to more adaptive responses to stress and negative affect $[7,4]$. Mindfulness was found to integrate "multiple neurological systems, including networks that regulate attention, working memory, somatic perception, and emotion" [7, p.203] to attenuate the craving for objects for addiction $[4,50,59,60]$. They also increased discriminative awareness and enabled the acceptance of uncomfortable states or challenging situations without habitual affective reaction [49]. Further, it reduced relapse as a result of changes in neural responses to negative affect and craving [50].

It was found that four important factors were contributory to the effectiveness of MBIs [28]. They were the type of MBI utilised, the 
disorder that was being targeted, the history of the participant and the embodiment of the mindfulness teacher. Competency of the teacher and emphasis of the participants' meditative experience were also found to be contributory [38]. Therapeutic alliance was also another factor for success $[61,54]$. Demarzo, Cebolla and Garcia-Campayo [19] found three key requirements for professional MBI training for teachers which were " $i$. content, method and process of development and training; ii. training standards; and iii. the definition of skills needed to teach mindfulness groups and/or train other instructors" (p.167).

There were incidences of adverse effects. A few case studies on MBIs recorded occurrences of psychotic episodes which involved mindfulness related programmes but not exclusively mindfulnessbased. However, the majority of such participants with such effects had a history of mental illness.

Results of MBIs could also have had research biases. stated that qualitative research results of MBIs could have been influenced by the researcher's epistemological biases. Most of the MBIs were also found to focus on a limited range of psychopathologies.

\section{Substance misuse}

A significant number of studies have been conducted with MBIs on substance abuse [51]. Consistent positive effects were found with MBIs on substance abuse with adults and treatment outcomes [51].

Individuals who participated in MBIs reported no increase in craving or substance use due to negative affect [50,49]. MBIs were more effective than 'treatment as usual' in reducing the amount and frequency of substance use [51,62,49,54,63-68]. Other effects were thought suppressions [51], reduced psychiatric distress/symptoms $[51,69,64]$, reduced negative emotions and moods [51,69] reduced craving $[51,54,70,66]$, reduction of stress $[51,63]$, increase in substance use related locus-of-control [51], increased optimism [51], better working memory $[51,62]$, better response inhibition [51,62], reduced addiction severity [71] and better decision making [51,62]. MBIs also reduced withdrawal symptoms [72] and relapse [68].

Asl and Hosseinalipour [73] found MBIs effecting positive secondary outcomes such as vitality, mental health, social functioning, role emotional and bodily pain. Legal problems [67], depression $[69,63,66]$, anxiety [63], eating disorder [63], disassociation [63], psycho-social outcomes [64] and medical problems [67] were also found to have improved. Individuals were also found to have increased acceptance [54] and awareness [54].

Race was also found to have an impact on the reduced substance use and addiction severity [71]. MBIs were also well received with satisfaction by the participants [74]. Dispositional mindfulness was also found to be associated with less self-medication for mitigating negative affect [75]

Individuals who participated in MBIs spent more time in home practice and thus lowered substance use [59]. MBIs were found to be more effective with stimulant dependent adults with mood and anxiety disorders [59], also effective with individuals with co-morbidd epression [76,69] and substance use disorders [76]. Hence, MBIs as an aftercare intervention were found to be effective [54].

Int J Psychol Behav Anal

ISSN: 2456-3501
However, there appears to be a lack of research in examining the mechanisms behind mindfulness interventions and how it gets effected [51] as well as qualitative studies [77].

\section{Alcoholism}

Consistent positive findings were found with regard to MBIs on alcohol addiction with adults [51] as well as with supplementary therapy with relapse prevention $[49,78]$. Positive results were also found with those released from prison when compared with treatment as usual [64]. Decrease in problems and psychiatric symptoms with alcohol as well as increase in positive psychosocial outcomes were also found [64].

MBIs lowered risk of relapse to alcoholism and reduced days of heavy drinking $[68,79]$ compared to 'treatment as usual'. Paulus et al. [49] found lower attentional biases, reduced stress and reduced craving. Self-efficacy was also found to have improved $[49,80]$. Participants of MBIs were also found to spend more time at home [59] thus leading to lower alcohol abuse. Better and healthier choices and more freedom with regards to choosing alternatives when facing interpersonal threats and disappointments were also recorded [81]. MBIs were also found to weaken the automatic neural processes that were related to alcohol use [79].

The awareness component of mindfulness negatively related to alcohol use but positively related to alcohol related consequences [82]. The acceptance component was negatively related to alcohol related consequences [82].

Individuals with lower distress tolerance were found to experience decrease in alcohol use over time than 'treatment as usual' for about 4 months after treatment [83]. Individuals with higher levels of trait mindfulness were found to use less alcohol, and reported less stress and craving, and the ability to resist the urge in high risk situations [80].

\section{Problem gambling}

MBIs were found to have a significant impact on individuals with gambling addiction [83]. They were found to be useful in avoidance, disassociation, impulse attenuation, induced positive thinking, reduced conflict; and reduced relapse [84].

Shonin, Van Gordon, \& Griffiths [85] found that MBIs also reduced urges, gambling severity and emotional distress. Better clinical outcomes [86] and temper withdrawal symptoms [84] were also found. Gratitude and hope were found to be negatively related to gambling, gambling related thinking and urges [87].

\section{Smoking cessation}

MBIs were found to have a better effect on smoking cessation than current treatments [36,57] and Cognitive Behavioural Therapy [57] in preventing relapses. MBIs reduced craving $[7,88]$ and increased rates of post-treatment abstinence $[51,88,36,89]$.

Individuals were found to have reduced negative affect, reduced depressive symptoms, and reduction in nicotine dependence [90]. MBIs also resulted in reduced use $[88,36]$ and coping strategies for triggers [88]. More activity in the neural networks associated with self-control were found with individuals [60]. Generally, MBIs were found to be superior to treatment as usual $[51,57]$. 
Citation: Kathirasan K (2018) The Role of Mindfulness in Treating Addictive Disorders and Rehabilitation. Int J Psychol Behav Anal 4: 155. doi: https:/doi. org/10.15344/2455-3867/2018/155

Page 5 of 7

\section{Workaholism}

There has been significantly less research on workaholism and MBIs. Limited literature found that MBIs broadened perspectives, induced re-evaluation of life priorities, balanced the level of organisational identification, enhanced work engagement, reduced work duration and reduced psychological distress [91]. It was found that individuals reduced working hours without impacting job performance and had better job satisfaction [92].

\section{Sex addiction}

Limited studies have been done with individuals with sex addiction and disorders. Van Gordon, Shonin, \& Griffiths [93] found that MBIs improved secondary outcomes such as sleep quality and job satisfaction. Disassociation to experiences $[93,94]$ and reduced problematic sexual fantasies, urges, anxiety, depression, impulsivity, stress [94] were also found with MBIs.

\section{Discussion}

From the various descriptions and definitions of mindfulness practices, three primary components appear to be significant, which were attention $[1,2,4,5,7,9]$, acceptance $[3,7,11,49,54,82]$ and awareness $[2,8,11,28,49,54,82]$. Therefore, mindfulness is the disposition and practice of awareness, attention and acceptance. More focus and study could be given to these components thus allowing a more focused and targeted design of MBIs to achieve positive outcomes.

MBIs were generally found to be better than 'treatment as usual' for addictive disorders. MBIs significantly impacted the neural networks related to addictive disorders to achieve treatment outcomes. These appear to be the primary impact of all MBIs where neurological networks related to craving, reactivity and compulsive use are weakened, thereby strengthening response, awareness and acceptance. Individuals with co-morbid mood, anxiety disorders and depression were also known to benefit from MBIs.

The positive effects of MBIs are consistent across the types of addictive disorders studied. It included stress reduction, reduced urges and craving, and reduced impact of negative affect. MBIs were also known to impact secondary outcomes in the areas of social outcomes, mental health, and dealing with pain amongst others.

Trait or dispositional mindfulness has been found to be the objective of all MBIs. Trait mindfulness were found to be associated with reduced use, reduced stress, craving and resist urges. More studies are needed in the area of measuring trait mindfulness so that more progress could be made in rehabilitation of addictive disorders.

Contrary to the views of Shonin and Van Gordon [28], the type of MBI employed did not appear to be as important as all of them consistently had positive outcomes. But exception has to be made to mindfulness related programmes which had created psychotic episodes. Regardless of the diverse nature and design of the MBIs, the same or similar mindfulness practices were involved.

Some of the MBIs varied from one another by the additional components fused into it. Components such as cognitive behavioural therapy (CBT), positive psychology, traditional relapse prevention strategies and buddhistic ontological investigations were coupled with mindfulness practices. However, at this point it can be speculated that the cause of structural brain changes were primarily the mindfulness practices rather than the additional components. More studies are required to delineate the impact areas of mindfulness practices and the additional components built into MBIs.

The integrity of MBIs largely depended on the targeted disorder, history of the participant, competence and embodiment of the teacher, the emphasis laid on meditation by the participants and therapeutic alliance.

Adverse effects were largely unknown with MBIs, except with individuals with a history of mental illness or due to loosely designed programmes incorporating mindfulness. MBIs were also known to cause an addiction to mindfulness itself.

Most of the studies on the effectiveness of MBIs have been on substance misuse and alcoholism. More studies are needed on workaholism and sex addiction. More qualitative and longitudinal studies are recommended to better understand the long term impact of mindfulness on relapse prevention.

\section{Competing Interests}

The author declare no competing interests.

\section{References}

1. Kabat-Zinn J (1994) Wherever you go, there you are: Mindfulness meditation for everyday life. New York: Hyperion.

2. Kabat-Zinn J (2003) Mindfulness-based interventions in context: Past, present, and future. Clinical Psychology: Science and Practice 10: 144-156.

3. Richmond K, Zerbo E, Levounis P (2016) What Is Mindfulness?. Becoming Mindful: Integrating Mindfulness Into Your Psychiatric Practice. USA: American Psychiatric Association Publishing.

4. Garland EL, Froeliger B, Howard MO (2014a) Mindfulness training targets neurocognitive mechanisms of addiction at the attention-appraisalemotion interface. Front Psychiatry 4: 173.

5. Dickenson J, Berkman ET, Arch J, Lieberman MD (2012) Neural correlates of focused attention during a brief mindfulness induction. Soc Cogn Affect Neurosci 8: 40-47.

6. Uusberg $H$, Uusberg A, Talpsep T, Paaver M (2016) Mechanisms of mindfulness: the dynamics of affective adaptation during open monitoring. Biol Psychol 118: 94-106.

7. Houlihan SD, Brewer JA (2016) The emerging science of mindfulness as a treatment for addiction. In Mindfulness and Buddhist-derived approaches in mental health and addiction. Springer, Cham.

8. Capobianco L, Reeves D, Morrison AP, Wells A (2018) Group Metacognitive Therapy vs. Mindfulness Meditation Therapy in a Transdiagnostic Patient Sample: A Randomised Feasibility Trial. Psychiatry Res 259: 554-561.

9. Shapiro SL, Carlson LE, Astin JA, Freedman B (2006) Mechanisms of mindfulness. J Clin Psychol 62: 373-386.

10. Brown KW, Ryan RM, Creswell JD (2007) Mindfulness: Theoretical foundations and evidence for its salutary effects. Psychological Inquiry 8 : 211-237.

11. Baer RA (2003) Mindfulness training as a clinical intervention: A conceptual and empirical review. Clinical Psychology: Science and Practice 10: 125-143.

12. Baer RA, Smith GT, Hopkins J, Krietemeyer J, Toney L, et al. (2006) Using selfreport assessment methods to explore facets of mindfulness. Assessment 13: 27-45.

13. Kabat-Zinn J (2013) Full catastrophe living: Using the wisdom of your body and mind to face stress, pain, and illness. Random House Publishing Group. 
Citation: K K (2018) The Role of Mindfulness in Treating Addictive Disorders and Rehabilitation. Int J Psychol Behav Anal 4: 152. doi: https://doi. org/10.15344/2455-3867/2018/152

Page 6 of 7

14. Martin KP, Blair SM, Clark GI, Rock AJ, Hunter KR, et al. (2018) Trait Mindfulness Moderates the Relationship Between Early Maladaptive Schemas and Depressive Symptoms. Mindfulness 9: 140-150.

15. Carmody J, Baer RA (2008) Relationships between mindfulness practice and levels of mindfulness, medical and psychological symptoms and well-being in a mindfulness-based stress reduction program. J Behav Med 31: 23-33.

16. Kiken LG, Garland EL, Bluth K, Palsson OS, Gaylord SA, et al. (2015) From a state to a trait: trajectories of state mindfulness in meditation during intervention predict changes in trait mindfulness. Personality and Individual differences 81: 41-46.

17. Cullen M (2011) Mindfulness-based interventions: An emerging phenomenon. Mindfulness 2: 186-193.

18. Gu J, Strauss C, Bond R, Cavanagh K (2015) How do mindfulness-based cognitive therapy and mindfulness-based stress reduction improve menta health and wellbeing? A systematic review and meta-analysis of mediation studies. Clin Psychol Rev 37: 1-12.

19. Demarzo MMP, Cebolla A, Garcia-Campayo J (2015) The implementation of mindfulness in healthcare systems: a theoretical analysis. Gen Hosp Psychiatry 37: 166-171.

20. Grossman P, Niemann L, Schmidt S, Walach H (2004) Mindfulness-based stress reduction and health benefits: A meta-analysis. J Psychosom Res 57 $35-43$.

21. Van Gordon W, Shonin E, Griffiths MD (2015) Towards a second generation of mindfulness-based interventions. Aust N Z J Psychiatry 49: 591-592.

22. Morgan D (2003) Mindfulness-based cognitive therapy for depression: A new approach to preventing relapse. New York, NY, US: Guilford Press.

23. Teasdale JD, Segal ZV, Williams JMG, Ridgeway VA, Soulsby JM, et al. (2000) Prevention of relapse/recurrence in major depression by mindfulnessbased cognitive therapy. J Consult Clin Psychol 68: 615-623.

24. Alsubaie M, Abbott R, Dunn B, Dickens C, Keil TF, et al. (2017) Mechanisms of action in mindfulness-based cognitive therapy (MBCT) and mindfulnessbased stress reduction (MBSR) in people with physical and/or psychological conditions: A systematic review. Clin Psychol Rev 55: 74-91.

25. Crane R (2009) Mindfulness-Based Cognitive Therapy. USA: Routledge.

26. Shonin E, Van Gordon W, Griffiths M (2013) Mindfulness-based interventions: Towards mindful clinical integration. Front Psychol 4: 194.

27. Chiesa A, Malinowski P (2011) Mindfulness-based approaches: are they al the same?. J Clin Psychol 67: 404-424.

28. Shonin E, Van Gordon W (2016) The mechanisms of mindfulness in the treatment of mental illness and addiction. International journal of mental health and addiction 14: 844-849.

29. Hölzel BK, Carmody J, Evans KC, Hoge EA, Dusek JA, et al. (2009) Stress reduction correlates with structural changes in the amygdala. Soc Cogn Affect Neurosci 5: 11-17.

30. Hölzel BK, Carmody J, Vangel M, Congleton C, Yerramsetti SM, et al. (2011) Mindfulness practice leads to increases in regional brain gray matte density. Psychiatry Res 191: 36-43.

31. Pickut BA, Van Hecke W, Kerckhofs E, Mariën P, Vanneste S, et al. (2013) Mindfulness based intervention in Parkinson's disease leads to structura brain changes on MRI: a randomized controlled longitudinal trial. Clin Neurol Neurosurg 115: 2419-2425

32. Tang YY, Hölzel BK, Posner MI (2015) The neuroscience of mindfulness meditation. Nat Rev Neurosci 16: 213-225.

33. Taren AA, Creswell JD, Gianaros PJ (2013) Dispositional mindfulness covaries with smaller amygdala and caudate volumes in community adults. PloS one 8: e64574.

34. Creswell JD (2017) Mindfulness interventions. Annual review of psychology 68: 491-516.

35. McConnell PA, Froeliger B (2015) Mindfulness, mechanisms and meaning: perspectives from the cognitive neuroscience of addiction. Psychol Inq 26 : 349-357.

36. Brewer JA, Mallik S, Babuscio TA, Nich C, Johnson HE, et al. (2011) Mindfulness training for smoking cessation: results from a randomized controlled trial. Drug Alcohol Depend 119: 72-80.
37. Josipovic Z (2014) Neural correlates of nondual awareness in meditation. Ann N Y Acad Sci 1307: 9-18.

38. Shonin E, Van Gordon W, Griffiths MD (2014a) Are there risks associated with using mindfulness for the treatment of psychopathology?.Clinical Practice, 11(4), 389-392.

39. Briñol P, Gascó M, Petty RE, Horcajo J (2013) Treating thoughts as material objects can increase or decrease their impact on evaluation. Psychol $\mathrm{Sci}$ 24: 41-47.

40. Wilson BM, Mickes L, Stolarz-Fantino S, Evrard M, Fantino E, et al. (2015) Increased false-memory susceptibility after mindfulness meditation. Psychol Sci 26: 1567-1573.

41. Brendel D (2015) There are risks to mindfulness at work. Harvard Business Review.

42. Lustyk, MK, Chawla N, Nolan R, Marlatt GA (2009) Mindfulness meditation research: issues of participant screening, safety procedures, and researcher training. Adv Mind Body Med 24: 20-30.

43. Crane RS, Brewer J, Feldman C, Kabat-Zinn J, Santorelli S, et al. (2017) What defines mindfulness-based programs? The warp and the weft. Psychol Med 47: 990-999.

44. Sussman S, Sussman AN (2011) Considering the definition of addiction. Int J Environ Res Public Health 8: 4025-4038.

45. Potenza MN (2006) Should addictive disorders include non-substancerelated conditions? Addiction 101: 142-151.

46. Grant JE, Chamberlain SR (2016) Expanding the definition of addiction: DSM-5 vs. ICD-11. CNS spectr 21: 300-303.

47. Volkow ND, Koob GF, McLellan AT (2016) Neurobiologic advances from the brain disease model of addiction. N Engl J Med 374: 363-371.

48. Buchman DZ, Illes J, Reiner PB (2011) The paradox of addiction neuroscience. Neuroethics 4: 65-77.

49. Paulus MP, Stewart JL, Haase L (2013) Treatment approaches for interoceptive dysfunctions in drug addiction. Front Psychiatry 4: 137.

50. Witkiewitz K, Lustyk MKB, Bowen S (2013c) Retraining the addicted brain: A review of hypothesized neurobiological mechanisms of mindfulness-based relapse prevention. Psychol Addict Behav 27: 351-365

51. Li W, Howard MO, Garland EL, McGovern P, Lazar M, et al. (2017) Mindfulness treatment for substance misuse: A systematic review and meta-analysis. Subst Abuse Treat 75: 62-96.

52. Garland EL, Manusov EG, Froeliger B, Kelly A, Williams JM, et al. (2014b). Mindfulness-oriented recovery enhancement for chronic pain and prescription opioid misuse: Results from an early-stage randomized controlled trial. J Consult Clin Psychol 82: 448-459.

53. Garland EL (2013) Mindfulness-oriented recovery enhancement for addiction, stress, and pain. NASW Press, National Association of Social Workers

54. Bowen S, Chawla N, Collins SE, Witkiewitz K, Hsu S, et al. (2009) Mindfulnessbased relapse prevention for substance use disorders: A pilot efficacy trial. Subst Abus 30: 295-305.

55. Price CJ, Hooven C (2018) Interoceptive Awareness Skills for Emotion Regulation: Theory and Approach of Mindful Awareness in Body-Oriented Therapy (MABT). Front Psychol 9: 798.

56. Price C, Smith-DiJulio K (2016) Interoceptive awareness is important for relapse prevention: perceptions of women who received mindful body awareness in substance use disorder treatment. J Addict Nurs 27: 32-38.

57. Vidrine JI, Spears CA, Heppner WL, Reitzel LR, Marcus MT, et al. (2016). Efficacy of mindfulness-based addiction treatment (MBAT) for smoking cessation and lapse recovery: A randomized clinical trial. J Consult Clin Psychol 84: 824-828.

58. Marlatt GA, Witkiewitz K, Dillworth TM, Bowen SW, Parks GA, et al. (2004) Vipassana meditation as a treatment for alcohol and drug use disorders. Mindfulness and acceptance: Expanding the cognitive-behavioral tradition.

59. Grow JC, Collins SE, Harrop EN, Marlatt GA (2015) Enactment of home practice following mindfulness-based relapse prevention and its association with substance-use outcomes. Addict Behav 40: 16-20.

60. Tang YY, Tang R, Posner MI (2016) Mindfulness meditation improves emotion regulation and reduces drug abuse. Drug Alcohol Depend 163: S13-S18.

Int J Psychol Behav Anal

ISSN: 2456-3501

IJPBA, an open access journal

Volume 4. 2018. 155 
Citation: K K (2018) The Role of Mindfulness in Treating Addictive Disorders and Rehabilitation. Int J Psychol Behav Anal 4: 152. doi: https://doi. org/10.15344/2455-3867/2018/152

Page 7 of 7

61. Bowen S, Kurz AS (2012) Between-session practice and therapeutic alliance as predictors of mindfulness after mindfulness-based relapse prevention. Clin Psychol 68: 236-245.

62. Alfonso JP, Caracuel A, Delgado-Pastor LC, Verdejo-García A (2011) Combined goal management training and mindfulness meditation improve executive functions and decision-making performance in abstinent polysubstance abusers. Drug Alcohol Depend 117: 78-81.

63. Price CJ, Wells EA, Donovan DM, Rue T (2012) Mindful awareness in body-oriented therapy as an adjunct to women's substance use disorde treatment: A pilot feasibility study. J Subst Abuse Treat 43: 94-107.

64. Bowen S, Witkiewitz K, Dillworth TM, Chawla N, Simpson TL, et al. (2006) Mindfulness meditation and substance use in an incarcerated population. Psychol Addict Behav 20: 343-347.

65. Alterman AI, Koppenhaver JM, Mulholland E, Ladden LJ, Baime MJ, et al. (2004) Pilot trial of effectiveness of mindfulness meditation for substance abuse patients. Journal of Substance Use 9: 259-268.

66. Witkiewitz K, Bowen S (2010) Depression, craving, and substance use following a randomized trial of mindfulness-based relapse prevention. $J$ Consult Clin Psychol 78: 362-374.

67. Witkiewitz K, Warner K, Sully B, Barricks A, Stauffer C, et al. (2014) Randomized trial comparing mindfulness-based relapse prevention with relapse prevention for women offenders at a residential addiction treatment center. Subst Use Misuse 49: 536-546.

68. Bowen S, Witkiewitz K, Clifasefi SL, Grow J, Chawla N, et al. (2014b) Relative efficacy of mindfulness-based relapse prevention, standard relapse prevention, and treatment as usual for substance use disorders: randomized clinical trial. JAMA psychiatry 71: 547-556.

69. Glasner S, Mooney LJ, Ang A, Garneau HC, Hartwell E, et al. (2017) Mindfulness-based relapse prevention for stimulant dependent adults: A pilot randomized clinical trial. Mindfulness 8: 126-135.

70. Witkiewitz K, Bowen S, Douglas H, Hsu SH (2013a) Mindfulness-based relapse prevention for substance craving. Addict Behav 38: 1563-1571.

71. Witkiewitz K, Greenfield BL, Bowen S (2013b) Mindfulness-based relapse prevention with racial and ethnic minority women. Addict Behav 38: 2821 2824.

72. Chen KW, Comerford A, Shinnick P, Ziedonis DM (2010) Introducing qigong meditation into residential addiction treatment: A pilot study where gender makes a difference. J Altern Complement Med 16: 875-882.

73. AsI NRH, Hosseinalipour F (2014) Effectiveness of mindfulness-based stress reduction intervention for health-related quality of life in drug-dependent males. Iran Red Crescent Med J 16: e12608.

74. Vallejo Z, Amaro H (2009) Adaptation of mindfulness-based stress reduction program for addiction relapse prevention. The Humanistic Psychologist 37 $192-206$.

75. Garland EL, Hanley AW, Thomas EA, Knoll P, Ferraro J, et al. (2015) Low dispositional mindfulness predicts self-medication of negative emotion with prescription opioids. J Addict Med 9: 61-67.

76. Zemestani M, Ottaviani C (2016) Effectiveness of mindfulness-based relapse prevention for co-occurring substance use and depression disorders. Mindfulness 7: 1347-1355.

77. Harris $\mathrm{AH}$ (2015) A qualitative study on the introduction of mindfulness based relapse prevention (MBRP) into a therapeutic community for substance abusers. Therapeutic Communities: The International Journal of Therapeutic Communities 36: 111-123.

78. Zgierska A, Rabago D, Zuelsdorff M, Coe C, Miller M, et al. (2008) Mindfulness meditation for alcohol relapse prevention: a feasibility pilot study. J Addict Med 2: 165-173.

79. Ostafin BD, Bauer C, Myxter P (2012) Mindfulness decouples the relation between automatic alcohol motivation and heavy drinking. Journal of Social and Clinical Psychology 31: 729-745.

80. Garland EL, Boettiger CA, Gaylord S, Chanon VW, Howard MO, et al. (2012) Mindfulness is inversely associated with alcohol attentional bias among recovering alcohol-dependent adults. Cognit Ther Res 36: 441-450.

81. Singer JA, Singer BF, Berry M (2013) A meaning-based intervention for addiction: using narrative therapy and mindfulness to treat alcohol abuse. In The experience of meaning in life. Springer, Dordrecht.
82. Fernandez AC, Wood MD, Stein LAR, Rossi JS (2010) Measuring mindfulness and examining its relationship with alcohol use and negative consequences. Psychol Addict Behav 24: 608-616.

83. Hsu SH, Collins SE, Marlatt GA (2013) Examining psychometric properties of distress tolerance and its moderation of mindfulness-based relapse prevention effects on alcohol and other drug use outcomes. Addict Behav 38: $1852-1858$.

84. Griffiths M, Shonin E, Van Gordon W (2016) Mindfulness as a treatment for gambling disorder: Current directions and issues. Journal of Gambling and Commercial Gaming Research 1: 47-52

85. Shonin E, Van Gordon W, Griffiths MD (2014c) Mindfulness as a treatment for behavioural addiction. Journal of Addiction Research \& Therapy 5: e122.

86. Toneatto T, Pillai S, Courtice EL (2014) Mindfulness-enhanced cognitive behavior therapy for problem gambling: A controlled pilot study. International Journal of Mental Health and Addiction 12: 197-205.

87. Loo JM, Tsai JS, Raylu N, Oei TP (2014) Gratitude, hope, mindfulness and personal-growth initiative: Buffers or risk factors for problem gambling? PloS one 9: e83889.

88. de Souza ICW, de Barros VV, Gomide HP, Miranda TCM, de Paula Menezes V et al. (2015) Mindfulness-based interventions for the treatment of smoking: a systematic literature review. J Altern Complement Med 21: 129-140.

89. Davis JM, Goldberg SB, Anderson MC, Manley AR, Smith SS, et al. (2014) Randomized trial on mindfulness training for smokers targeted to a disadvantaged population. Subst Use Misuse 49: 571-585.

90. Rogojanski J, Vettese LC, Antony MM (2011) Coping with cigarette cravings: Comparison of suppression versus mindfulness-based strategies. Mindfulness 2: 14-26.

91. Shonin E, Van Gordon W, Griffiths MD (2014b) The treatment of workaholism with meditation awareness training: A case study. Explore (NY) 10: 193-195.

92. Van Gordon W, Shonin E, Dunn TJ, Garcia-Campayo J, Demarzo MM, et al (2017) Meditation awareness training for the treatment of workaholism: A controlled trial. J Behav Addict 6: 212-220.

93. Van Gordon W, Shonin E, Griffiths MD (2016) Meditation awareness training for the treatment of sex addiction: a case study J Behav Addict 5: 363-372.

94. Reid RC, Bramen JE, Anderson A, Cohen MS (2014) Mindfulness, emotional dysregulation, impulsivity, and stress proneness among hypersexual patients. J Clin Psychol 70: 313-321.

Int J Psychol Behav Anal

ISSN: 2456-3501

IJPBA, an open access journal

Volume 4. 2018. 155 